\title{
Entrevista com Roque Rodrigues
}

\section{Maria Raquel Freire e Roque Rodrigues}

\section{(2) OpenEdition}

\section{Journals}

Edição electrónica

URL: http://journals.openedition.org/rccs/5744

DOI: $10.4000 /$ rccs. 5744

ISSN: 2182-7435

\section{Editora}

Centro de Estudos Sociais da Universidade de Coimbra

Edição impressa

Data de publição: 1 Setembro 2014

Paginação: 175-180

ISSN: 0254-1106

\section{Refêrencia eletrónica}

Maria Raquel Freire e Roque Rodriques, «Entrevista com Roque Rodrigues », Revista Crítica de

Ciências Sociais [Online], 104 | 2014, colocado online no dia 23 setembro 2014, criado a 20 abril 2019 URL : http://journals.openedition.org/rccs/5744; DOI : 10.4000/rccs.5744 


\title{
Entrevista com Roque Rodrigues
}

\author{
MARIA RAQUEL FREIRE
}

Roque Rodrigues é uma figura incontornável da vida política timorense, com um historial de vida que atesta quanto ao seu envolvimento e compromisso para com Timor-Leste. Sempre presente nos momentos mais difíceis da história deste país, tem também partilhado todos os bons momentos no processo de construção e consolidação do Estado, do qual fala com orgulho sentido. No seu habitual tom cordial e bem-humorado, Roque Rodrigues, assessor da Presidência da República de Timor-Leste, concedeu-nos esta entrevista no dia 18 de janeiro de 2014, refletindo sobre o papel de atores domésticos e externos e as dinâmicas na sua interseção para a construção da paz em Timor-Leste; analisando o passado e o futuro do país; e falando sobre oportunidades e desafios que se apresentam para o futuro.

No seu entender, qual o legado mais marcante da Administração Transitória (UNTAET) para o que é boje Timor-Leste?

Respondo de duas maneiras. Primeiro, a UNTAET ajudou a liderança timorense a retomar o Estado, ou seja, nós tínhamos proclamado a república, mas as estruturas republicanas pereceram com a guerra; o Estado, o seu aparelho, as suas estruturas foram sendo desmanteladas pela ocupação militar indonésia. Portanto, para nós o que eles [UNTAET] estavam a fazer era ajudar a restruturar, a restabelecer, a recompor o Estado e as suas estruturas. Como a ONU nunca reconheceu o Estado timorense, para eles [missão no terreno] tratava-se, por um lado, de limpar a destruição que tinha sido feita pela Indonésia, particularmente na fase final. Por outro lado, ajudar a construir, a moldar os alicerces da república, do Estado republicano que nós queríamos reconhecido internacionalmente. Esta é a minha primeira perspetiva, relativa ao trabalho marcante da UNTAET, que na altura se centrava em ajudar a nossa nação a repor a estabilidade. Para eles, significava 'limpar' o que a Indonésia tinha deixado destruído.

Segundo, foi preciosa a ação da UNTAET na inserção de Timor como Estado. Seria mais difícil para as autoridades do país obterem reconhecimento regional e internacional sem o apoio das Nações Unidas, e nomeadamente da Administração Transitória. As Nações Unidas desempenharam tarefas essenciais em Timor-Leste. No cerne destas, o Estado, ter os alicerces 
para o Estado, e tarefa inevitável e incontornável foi, proceder à sua inserção na sub-região e na região, com o beneplácito da ONU. Ou seja, com a presença do mais alto mandatário da ONU no dia 20 de maio, que é o dia em que para nós foi restaurada a independência do Estado nacional, para eles reconhecida a nossa independência. Timor-Leste passou então a ser aceite na comunidade internacional.

Atendendo à sua participação e ao envolvimento direto no processo de consolidação do Estado depois de anos de ocupação e resistência, que leitura faz do curso que Timor-Leste tem prosseguido? Quais são, no seu entender, os principais desafios que o país enfrenta?

Aqui está uma pergunta difícil. Consolidar as estruturas do Estado é um processo que leva anos. Ou seja, as independências conquistam-se e as independências perdem-se. Para que não se perca esta capacidade de exercer soberanamente decisões, fazer escolhas sobre o futuro do país, é necessário saber manter a independência. Portanto, se nós entendemos que o que dá sentido à luta é a independência conquistada, isto significa manter soberania, significa consolidar o Estado, reforçar a independência. Então, provavelmente, este é o grande desafio, é saber consolidar a independência e aceitar as várias falhas, os vários desafios, as várias tarefas que em vários domínios o país enfrenta. Vou dar um exemplo apenas, na área da economia. Timor-Leste é um país abençoado pela natureza. Tem em primeiro lugar o povo que se mostrou hábil, capaz de resistir à pressão, capaz de ser criador e fazer face aos piores desafios, e de contestar um vizinho. Por outro lado, se olharmos para o território, o território é rico, e o mar também. Então, construir uma independência ou consolidar a independência obriga-nos a tarefas que dizem respeito ao alicerçar da economia em bases sólidas. Uma delas é aproveitar de uma maneira equilibrada e sustentada os recursos com que a natureza nos brindou. Estou a falar dos recursos da terra e dos recursos do mar. Timor está inserido numa zona onde se encontra a maior extensão coralífera do mundo. Nós somos um dos seis países do que é denominada a Iniciativa do Triângulo Coralífero, em inglês Coral Triangle Initiative. Estamos ao pé da Austrália que é um país que faz face à maior barreira de coral do mundo. Por outro lado, o país dispõe de recursos no mar, de petróleo e de gás; então, alicerçar a nossa economia, dar um sentido de autossuficiência e respeitar o ambiente são tarefas que nós temos pela frente. Isso obriga a outra coisa, que é diversificar, evitar a dependência. Timor tem todas as condições para ser autossuficiente do ponto de vista marinho, mas faltam recursos humanos. Como aproveitar o potencial que o país tem se não lançarmos as bases de uma estratégia de valorização de recursos humanos? Este é provavelmente o maior desafio para Timor-Leste. Este caminho tem sido percorrido, contudo nós não podemos dizer que é um caminho fácil porque nos primeiros anos da independência o país sofreu e conheceu alguns sobressaltos. Eu digo que a consolidação das instituições é um processo que demora tempo. Estou convencido de que nós estamos no bom caminho. É inevitável estarmos na esteira, na senda da consolidação das nossas instituições. Não é apenas um processo de consolidação, mas também de reforço do seu caráter, ou seja, nós queremos um 
Estado democrático, o que significa lidar bem com a diversidade, garantir a pluralidade de vozes e de opções, dentro daquilo que a Constituição permite. Não é o caos, não é o democratismo, há prin-cípios que têm de ser respeitados, mas o respeito por esses princípios faz-se de acordo com a cultura, que é o itinerário, o roteiro que Timor já percorreu. Eu não espero ver implantada em Timor a democracia num curto espaço de tempo, não é possível. Outros levaram provavelmente 600 anos para chegarem onde estão, nós estamos apenas com 10, 11 anos, vamos fazer 12, de restauração do nosso Estado, portanto é um caminho que vai sendo feito.

Sendo mais ousado vou referir ainda um outro desafio. A democracia não serve se as condições de vida do povo não forem alteradas substancialmente. Nenhuma democracia o é enquanto houver pobres. Nós estamos com uma taxa de pobreza grande. Não quero especificar números, porque não coincidem e não sei em quem confiar, mas os últimos dados que obtive ontem mostram que a nível da pobreza extrema, 'extreme poverty', estamos perto dos $10 \%$. Enquanto $10 \%$ dos cidadãos viverem em extrema pobreza não é possível falar-se em democracia, e muito menos numa democracia perfeita. Este princípio é válido para Timor como é válido para os Estados Unidos. Daí que privilegiar os direitos em democracia sem pensar no bem-estar dos cidadãos é demagogia.

A saída da UNMIT tem sido veiculada como marcando um momento fundamental na bistória do país, e na sua afirmação como Estado independente e autónomo, com politicas sustentáveis. Entende que a estabilidade e a paz estão consolidadas e que as políticas mais recentes de ajuda ao desenvolvimento, como no caso da Guiné-Bissau, ou a maior integração a nivel regional, por exemplo, são demonstrativas disso mesmo? E a nível interno, onde os indicadores de desenvolvimento são ainda frágeis?

A paz é um desafio permanente. Eu não creio que a paz seja, e vou usar a expressão inglesa uma vez que capta melhor o sentido que pretendo dar ao conceito, uma espécie de political commodity. É um bem precioso, é uma condição sine qua non, mas obriga, tal como o amor a uma prática diária, a que a flor seja regada diariamente. Nenhum país, e nós vimos mesmo isto em países ditos consolidados, quando descuraram, quando deixaram de olhar para o processo de consolidação da paz de uma maneira holística, integrada, escapou a um processo em que as pessoas se viram a pouco e pouco despojadas das condições mais básicas de vida. Estou a falar por exemplo da pobreza que atinge a Europa. O problema da paz, o problema da estabilidade são coisas, e eu vou responder um pouco como os chineses, vou ser um pouco cínico, talvez mais irónico do que cínico. Uma vez perguntaram ao falecido primeiro-ministro chinês Chu Enlai o que ele pensava da Revolução Francesa e Chu Enlai respondeu assim: 'É muito cedo para falarmos nisso'. Eu vou responder à questão com ironia, é um pouco cedo falarmos da paz e estabilidade em Timor. Olho para o mundo e não é um problema de Timor. Quando teóricos como Fukuyama já diziam que a história tinha acabado, não havia mais nada a fazer porque a história havia terminado, apareceu uma ofensiva terrorista, a paz foi minada. Pergunto se esta irradiação do extremismo religioso, do fanatismo, refletido em ações violentas, se não é um atentado, se não nos leva uma vez mais 
à questão de quais são os fundamentos da paz? De como se alcança a paz? E a paz não se faz sem justiça, sem inclusão. Portanto, políticas inclusivas, políticas de justiça social (a designação inglesa traduz melhor o conceito de social equity), só isto é condição base e sine qua non para termos estabilidade e paz.

Relativamente a indicadores de desenvolvimento: é verdade, uma coisa é um país frágil, outra coisa é um país falhado ou em rota de falhanço. Eu digo assim, o meu país é frágil mas está longe de ser um país falhado. Mas frágeis somos todos nós! Se quiser olhar por um outro ângulo, quando olhamos a velocidade a que se processa a dinâmica de globalização, então todos nós somos Estados frágeis. Pergunto uma coisa: o abalo nos EUA e a recessão desde 2008 não mostrou fragilidade? Se não quisermos falar de fragilidade, ou mesmo de vulnerabilidade, no mínimo podemos falar da resiliência do sistema económico e financeiro, que não foi, de facto, suficientemente resiliente. Os EUA apresentam um défice significativo: no sistema bancário já ultrapassa a base dos triliões. Não colapsaram, mas não foram suficientemente resilientes. Como é que podemos exigir de Timor estabilidade e paz asseguradas? Podemos é dizer que estamos no bom caminho. Todo o trabalho desenvolvido dentro do sistema visa produzir justiça social, e este está a ser feito, mas há ainda muito para fazer. Quanto a fragilidade, sim, nós ainda somos um país frágil, mas é por isso que nos atrevemos a assumir a liderança de um grupo de 18 países, que se chama g7+. Todos eles reúnem duas condições: são países pós-conflito (post-conflict societies), e são também Estados frágeis, cujas sociedades ainda revelam vulnerabilidade, e por isso é precisa atenção especial a estas questões.

Qual entende ser o principal contributo de Portugal em todo este processo e que papel potencial ou real considera que Portugal poderia ou pode ainda ter no processo de consolidação da paz em Timor-Leste?

O principal contributo de Portugal pode ser lido de duas maneiras; se estivermos a falar apenas do processo que teve lugar e que ficou conhecido como de transição, é uma coisa, se estivermos a falar no processo que precedeu à fase de transição, a resposta é mais longa. Mas diria que foi essencial, foi substancial a participação de Portugal no processo de transição. Toda a parte da componente militar, o maior número de ações, de agentes que nos ajudaram na retoma das funções do Estado e no processo de inserção de Timor no conjunto de Estados soberanos, aí Portugal teve um papel notável.

Por outro lado, qualquer pessoa que estude o processo de transição vai deparar-se com Portugal e o seu legado em Timor-Leste, as suas obras e ações. O que se pode fazer? Setores como a justiça, a solidariedade social, a administração pública são fundamentais, mas honestamente, a partir deste ano Timor-Leste vai assumir a X Cimeira ou a X Conferência dos países membros de língua portuguesa, e eu diria que o principal papel que eu gostaria de ver da parte de Portugal neste âmbito seria de agir com os outros Estados-Membros no espírito comunitário, ou seja, no espírito da CPLP, no que diz respeito à língua portuguesa. Porquê? Portugal é um país que depois de aceitar o mirandês como língua oficial, de forma inclusiva, se revela praticamente um país monolingue; Timor-Leste é plurilingue. Esta experiência é um desafio para nós, mas é também um desafio 
à comunidade e a Portugal. Os maiores recursos a nível linguístico estão em Portugal e no Brasil, e por isso mesmo o vocabulário ortográfico nacional tem a sua maior expansão e desenvolvimento nestes dois países, no Brasil e em Portugal. Poderíamos ter um papel de Portugal e do Brasil, no que diz respeito à reintrodução da língua portuguesa e à sua parceria estratégica com o tétum, porque o tétum tem de se afirmar como língua de todos nós, pois é língua Constitucional, e porque ele - tétum - vai enriquecer com o convívio estratégico com a língua portuguesa. 
